\title{
Mechanically induced crystallization of an amorphous CoFeZrB alloy
}

\author{
J. Bednarčík ${ }^{a)}$ and E. Burkel \\ Institute of Physics, University of Rostock, August-Bebel-Straße 55, D-18055 Rostock, Germany \\ K. Saksl \\ Deutsches Elektronen Synchrotron (HASYLAB), Notkestraße 85, D-22607 Hamburg, Germany \\ P. Kollár \\ Department of Condensed Matter Physics, Faculty of Science, P.J. Šafárik University, Park Angelinum 9, \\ 04154 Košice, Slovakia \\ S. Roth \\ IFW Dresden, Institut für Metalische Werkstoffe, Helmholtzstraße 20, D-01069 Dresden, Germany
}

(Received 8 November 2005; accepted 2 April 2006; published online 5 July 2006)

\begin{abstract}
The short-time $\left(12 \mathrm{~h}\right.$ ) ball milling of the amorphous $\mathrm{Co}_{56} \mathrm{Fe}_{16} \mathrm{Zr}_{8} \mathrm{~B}_{20}$ (at. \%) alloy resulted in the formation of bcc-Fe nanocrystals embedded in an amorphous matrix. X-ray diffraction (XRD) using synchrotron radiation, differential scanning calorimetry (DSC), vibrating sample magnetometery (VSM), and the Faraday magnetic balance experiments were used to characterize the materials. XRD and DSC show that the fraction of crystallized bcc-Fe gradually increases with the milling time. The VSM measurements confirm the structure observations showing that the saturation magnetization increases with the milling time as the fraction of crystallized bcc-Fe increases. After $12 \mathrm{~h}$ of milling, the powder sample exhibited a Curie temperature of the amorphous phase $T_{C}^{\mathrm{am}}$, which is approximately $55 \mathrm{~K}$ higher compared to the as-quenched ribbon $\left(T_{C}^{\mathrm{am}}=601 \mathrm{~K}\right)$. Thermomagnetic measurements of heat-treated ribbons suggest that such an increase in $T_{C}^{\mathrm{am}}$ is not only due to temperature rises during the milling but may also be attributed to the combination of mechanical and thermal effects connected with the nature of milling. (C) 2006 American Institute of Physics. [DOI: 10.1063/1.2206890]
\end{abstract}

\section{INTRODUCTION}

Mechanical alloying by high-energy ball milling is a method for materials synthesis by solid state reactions and was developed about 40 years ago (see Ref. 1 for a recent review). During the milling process, elemental or alloy powders are subjected to high energetic impact forces, which results in repeated cold welding and fracture of the powder particles. The eventual interplay between fracture and rewelding leads to chemical homogenization, refinement of the particle size, disorder in the atomic structure, and, subsequently, formation of metastable phases. Ball milling (BM) is a simple and versatile processing technique to synthesize nonequilibrium materials such as amorphous phases, nanocrystalline phases, and extended solid solutions. ${ }^{1,2}$ This process has been used extensively to study the solid state amorphization of elemental powders and intermetallic compounds (see Chap. 11 of Ref. 1 and references therein). However, only a limited number of experiments were performed to explore the opposite, i.e., the structural transformation of amorphous alloys induced by ball milling. For example, Trudeau et al. reported the crystallization of Fe-based metallic glasses induced by high-energy ball milling. ${ }^{3}$ They concluded that the crystallization induced by mechanical deformation was not due to a thermal process and therefore should be treated separately from thermal stability. He et al. ob-

\footnotetext{
a) Also at the Department of Condensed Matter Physics, Faculty of Science, P.J. Šafárik University, Park Angelinum 9, 04154 Košice, Slovakia; electronic mail: bednarci@upjs.sk
}

served that $\mathrm{BM}$ of $\mathrm{Al}-\mathrm{Fe}-\mathrm{Gd}$ metallic glasses led to the formation of $\mathrm{Al}$ nanocrystals embedded in an amorphous matrix. ${ }^{4}$ They concluded that the atomic displacements induced by the large plastic strains and the enhancement of the atomic mobility during the deformation process are possible mechanisms of the mechanical deformation-induced crystallization. Furthermore, they pointed out that deformationinduced structural changes are sensitive to the chemical composition and thus to the atomic structure and the bonding nature of the metallic glasses.

For our investigations, we have chosen amorphous $\mathrm{CoFeZrB}$, which is known to exhibit a relatively wide supercooled liquid region and good soft magnetic properties. ${ }^{5}$ In a previous work ${ }^{6}$ we have shown that soft magnetic bulk amorphous materials can be prepared from a ball-milled CoFeZrB metallic glass by compacting the powder material just below the crystallization temperature in a supercooled liquid state. The present paper presents the experimental results on the mechanically induced crystallization of the CoFeZrB metallic glass by short-time BM.

\section{EXPERIMENT}

Amorphous ribbons with a nominal composition $\mathrm{Co}_{56} \mathrm{Fe}_{16} \mathrm{Zr}_{8} \mathrm{~B}_{20}$ (at. \%) were prepared by single-roller melt spinning. High-purity elements $(>99.9 \%)$ were used to prepare the starting prealloy. The as-quenched ribbons were cut into small pieces $\left(5 \times 10 \mathrm{~mm}^{2}\right)$ and milled up for $12 \mathrm{~h}$ using a RETSCH PM4000 planetary ball mill. The milling was 
done under argon atmosphere at a ball to powder weight ratio of 31:1 with a speed of $200 \mathrm{rpm}$. Hardened steel vials and balls were used. After each $2 \mathrm{~h}$ of milling a small amount of powder was removed for further investigations. All powder handling was done in a glove box under purified argon atmosphere (level of $\mathrm{O}_{2}, \mathrm{H}_{2} \mathrm{O}<1 \mathrm{ppm}$ ).

High-energy $\mathrm{X}$-ray diffraction (XRD) measurements were performed at HASYLAB at DESY (Hamburg, Germany) on the experimental station PETRA 2 using a monochromatic synchrotron radiation of $115 \mathrm{keV}$. The samples measured at a room temperature in the transmission mode were illuminated for $180 \mathrm{~s}$ by a well collimated incident beam of $1 \mathrm{~mm}^{2}$ cross section. XRD patterns were recorded using a two-dimensional (2D) detector (mar345 Image plate) in the asymmetric mode to obtain data at a high wave vector transfer $(Q=4 \pi \sin \theta / \lambda)$. The background intensity was subtracted directly from the 2D XRD pattern, and the result was integrated to the $Q$ space using the program FIT2D. ${ }^{7}$ The integrated data were corrected for polarization, sample absorption, fluorescence contribution, and inelastic scattering. The total structure factor $S(Q)$ was obtained using the FaberZiman equation. ${ }^{8}$

According to Faber-Ziman the total structure factor $S(Q)$ is obtained from the normalized elastically scattered intensity $I_{e}(Q)$ by the relation

$$
S(Q)=\frac{I_{e}(Q)-\left\langle f^{2}(Q)\right\rangle}{\langle f(Q)\rangle^{2}}
$$

where

$$
\langle f(Q)\rangle^{2}=\left(\sum_{i} c_{i} f_{i}(Q)\right)^{2}, \quad\left\langle f^{2}(Q)\right\rangle=\sum_{i} c_{i} f_{i}^{2}(Q) .
$$

Here $f_{i}(Q)=f_{0}(Q)+f^{\prime}(\lambda)+f^{\prime \prime}(\lambda)$ is the scattering length of the element $i, f^{\prime}(\lambda)$ and $f^{\prime \prime}(\lambda)$ are the anomalous dispersion terms which depend on the radiation wavelength, and $c_{i}$ is the atomic concentration of the element $i$. From the structure factor $S(Q)$, the total atomic pair distribution function $G(r)$ can be obtained by a sine Fourier transform:

$$
G(r)=4 \pi r\left[\rho(r)-\rho_{0}\right]=\frac{2}{\pi} \int_{Q_{\min }}^{Q_{\max }} Q(S(Q)-1) \sin (Q r) d r
$$

where $\rho(r)$ and $\rho_{0}$ are the local atomic density and average number density. From $G(r)$, the radial distribution function $\operatorname{RDF}(r)$ can be calculated by

$$
\operatorname{RDF}(r)=4 \pi \rho_{0} r^{2}+r G(r)
$$

The average coordination number $N$ around any given atom in a spherical shell between radii $r_{1}$ and $r_{2}$ can be calculated as

$$
N=\int_{r_{1}}^{r_{2}} \operatorname{RDF}(r) d r
$$

The thermal stability of the as-spun ribbons and of the ball-milled powders were examined at a heating rate of $10 \mathrm{~K} / \mathrm{min}$ by differential scanning calorimetry (DSC) using a NETZSCH DSC 404C. The saturation magnetization $\left(M_{S}\right)$

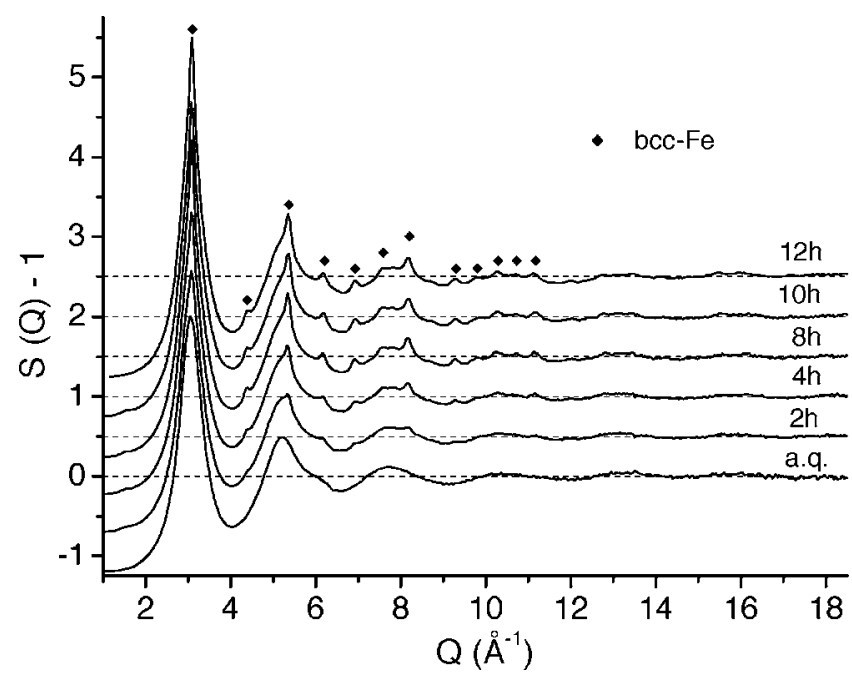

FIG. 1. Structure factors $S(Q)-1$ of the $\mathrm{Co}_{56} \mathrm{Fe}_{16} \mathrm{Zr}_{8} \mathrm{~B}_{20}$ alloy in asquenched state and milled for different times.

of selected samples was determined from the hysteresis loops measured at room temperature with a maximum field $H_{\max }$ $=1.6 \mathrm{MA} / \mathrm{m}$ with a vibrating sample magnetometer (VSM) LakeShore 735 . The thermomagnetic curves $M(T)$ of both as-spun ribbons and ball-milled powders were traced at $10 \mathrm{~K} / \mathrm{min}$ using a Faraday magnetic balance. The Curie temperature of the amorphous phase $\left(T_{C}^{\mathrm{am}}\right)$ was inferred from the $M(T)$ curve, fitting the data near the $T_{C}^{\mathrm{am}}$ to the critical law of the form $M(T) \propto\left(T_{C}^{\mathrm{am}}-T\right)^{\beta}$ with $\beta=0.36$ and extrapolating to $M(T)=0 .^{9}$ In order to clarify the role of temperature rises during $\mathrm{BM}$ we decided to investigate the influence of conventional annealing (at the temperatures below the crystallization temperature) on $T_{C}^{\mathrm{am}}$. Therefore a series of isochronal and isothermal annealing treatments of the as-quenched alloy were performed. The heat treatments were made in situ inside a Faraday magnetic balance. Once the piece of ribbon was placed in the magnetic balance, it was annealed at desired conditions (annealing temperature $T_{\text {an }}$ and time $t_{\text {an }}$ ). Afterwards, it was cooled down to room temperature, and finally the $M(T)$ curve was measured. From this $M(T)$ curve the corresponding value of $T_{C}^{\mathrm{am}}$ was extracted.

\section{RESULTS}

Figure 1 shows the total structure factors $[S(Q)-1]$ of the as-quenched $\mathrm{Co}_{56} \mathrm{Fe}_{16} \mathrm{Zr}_{8} \mathrm{~B}_{20}$ ribbon sample and of the powder samples milled for different times. The as-quenched sample exhibits a diffuse scattering pattern typical for metallic glasses with a maximum at $Q=3.06 \AA^{-1}$ and pronounced oscillations visible up to $Q \sim 15 \AA^{-1}$. The second broad peak at $Q \sim 5.2 \AA^{-1}$ has a shoulder at the high- $Q$ side which is again a common feature of structure factors of conventional metallic glasses. The $S(Q)$ taken from the sample milled for $2 \mathrm{~h}$ shows already small and broad Bragg peaks of the bcc-Fe phase (marked by signs) in addition to the diffuse amorphous contribution. The intensity of these peaks increases with the milling time. This indicates that the originally amorphous sample gradually crystallizes during the milling process. After $12 \mathrm{~h}$ of milling, the peaks (marked by signs) become more pronounced, but they are rather broad 

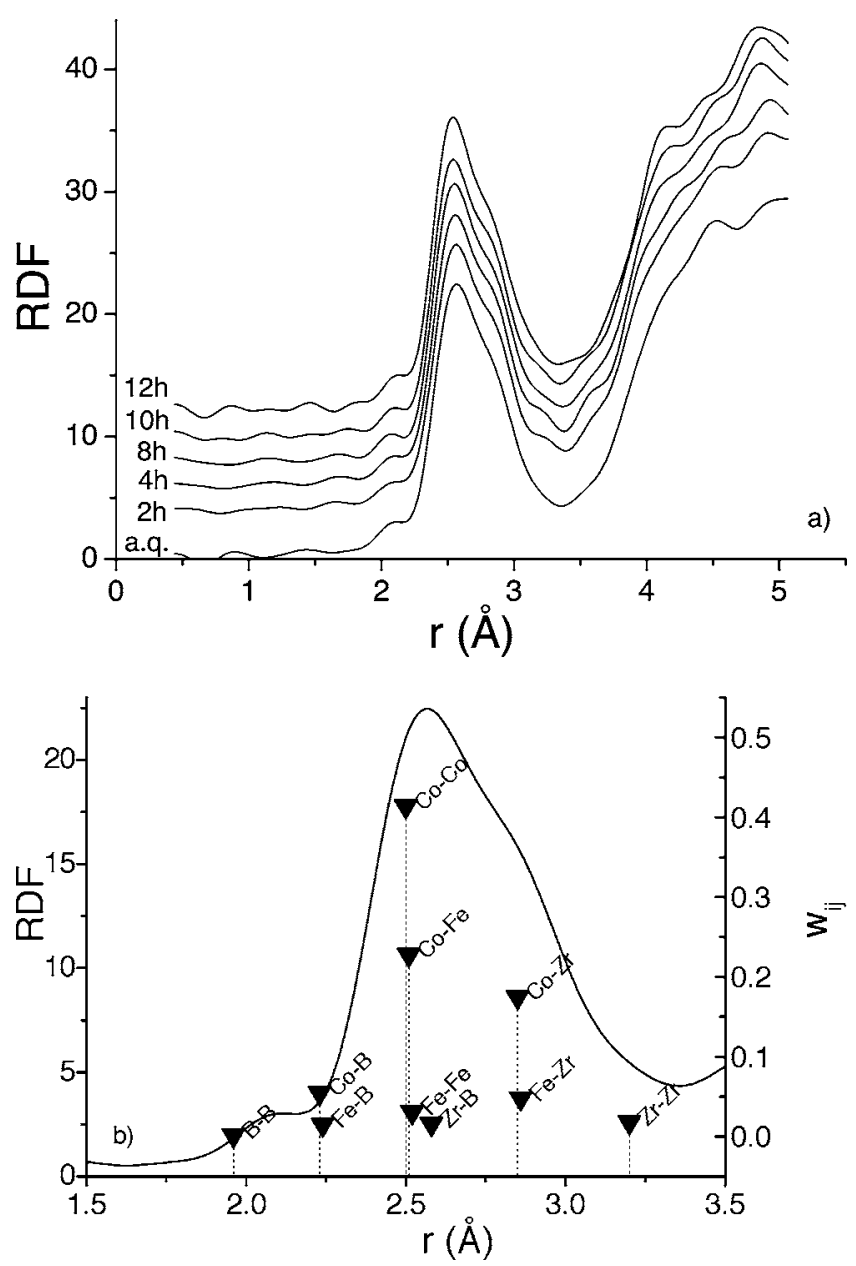

FIG. 2. (a) The radial distribution function (RDF) of the $\mathrm{Co}_{56} \mathrm{Fe}_{16} \mathrm{Zr}_{8} \mathrm{~B}_{20}$ alloy in the as-quenched state and after milling for various times. (b) The RDF of as-quenched $\mathrm{Co}_{56} \mathrm{Fe}_{16} \mathrm{Zr}_{8} \mathrm{~B}_{20}$ in the range of atomic distances of $1.5-3.5 \AA$ together with the interatomic bond lengths and corresponding weighting factors $w_{i j}$ calculated for $S\left(Q=1 \AA^{-1}\right)$.

[full width at half maximum (FWHM) $>0.2 \AA^{-1}$ ]. These observations suggest that a longer milling time increases the amount of crystalline fraction in the alloy, but the crystallites remain of nanometer size.

Figure 2(a) shows the RDF's calculated from the corresponding structure factors $S(Q)$ by applying Eqs. (3) and (4). Corresponding to $S(Q)$ curves, the shapes of the RDF curves are changing with the milling time. The common features for all of the distributions are a small prepeak located around $r$ $\sim 2.07 \AA$, a dominant peak $(r \sim 2.6 \AA)$ with a pronounced shoulder at the high $r$ side, and a deep minimum at $\sim 3.4 \AA$ determining the end of the first coordination sphere. Coordination numbers calculated from the first shell (range $1.78-3.4 \AA$ ) for all the samples are practically constant at $N=15 \pm 0.3$.

Figure 2(b) shows the RDF of the as-quenched $\mathrm{Co}_{56} \mathrm{Fe}_{16} \mathrm{Zr}_{8} \mathrm{~B}_{20}$ sample together with the interatomic bond lengths (sum of nominal atomic radii) and the corresponding weight factors. From the type and concentration of the constituent elements in the alloy, it is clear that the dominant atomic pairs determining the shape of the $\mathrm{x}$-ray RDF's are $\mathrm{Co}-\mathrm{Co}, \mathrm{Co}-\mathrm{Fe}$, and $\mathrm{Co}-\mathrm{Zr}$. The main peak is formed by $\mathrm{Co}-\mathrm{Co}$ and $\mathrm{Co}-\mathrm{Fe}$, while the shoulder could be assigned to

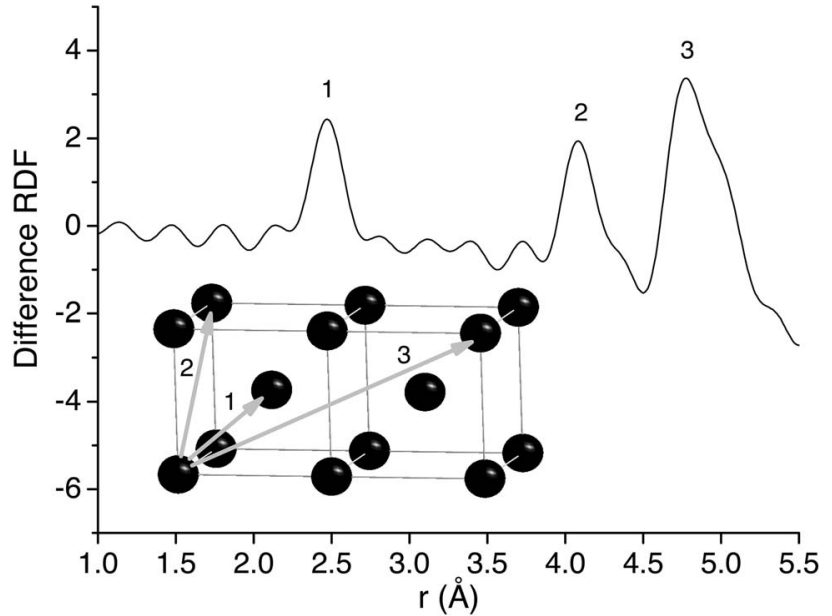

FIG. 3. The difference radial distribution function (RDF) $\left(\mathrm{RDF}_{12 \mathrm{~h}}\right.$ $\left.-\mathrm{RDF}_{\mathrm{aq}}\right) \cdot \mathrm{RDF}_{12 \mathrm{~h}}$ and $\mathrm{RDF}_{\mathrm{aq}}$ denote RDF's corresponding to a powder sample milled for $12 \mathrm{~h}$ and to the as-quenched alloy, respectively.

$\mathrm{Co}-\mathrm{Zr}$ atomic pairs. It may be interesting that the position of the maximum is slightly larger $(\sim 4 \%)$ than the sum of the nominal $\mathrm{Co}-\mathrm{Co}$ radii. On the other hand, the observed prepeak is formed by $\mathrm{Co}-\mathrm{B}$ atomic pairs. However, its position is $\sim 8 \%$ smaller than predicted. A similar prepeak was reported by Imafuku et al. ${ }^{10}$ for an amorphous $\mathrm{Fe}_{70} \mathrm{Co}_{10} \mathrm{~B}_{20}$ alloy. They suggested the presence of $(\mathrm{Fe}, \mathrm{Co})_{6} \mathrm{~B}$ trigonal prismatic units.

The difference between the RDF functions corresponding to the powder milled for $12 \mathrm{~h}$ and the as-quenched alloy is displayed in Fig. 3. The curve shows three distinct maxima corresponding to populated coordination shells in bcc-Fe (see figure insert).

The DSC scans of the as-quenched alloy and of the powder samples are shown in Fig. 4. A single-stage crystallization behavior, indicated by the presence of a sharp exothermic peak with the onset temperature $T_{x}=890 \mathrm{~K}$, is characteristic for all samples. As can be seen from the inset in Fig. 4 , the crystallization enthalpy $\Delta H_{x}$ tends to decrease exponentially with the milling time $t_{m}$.

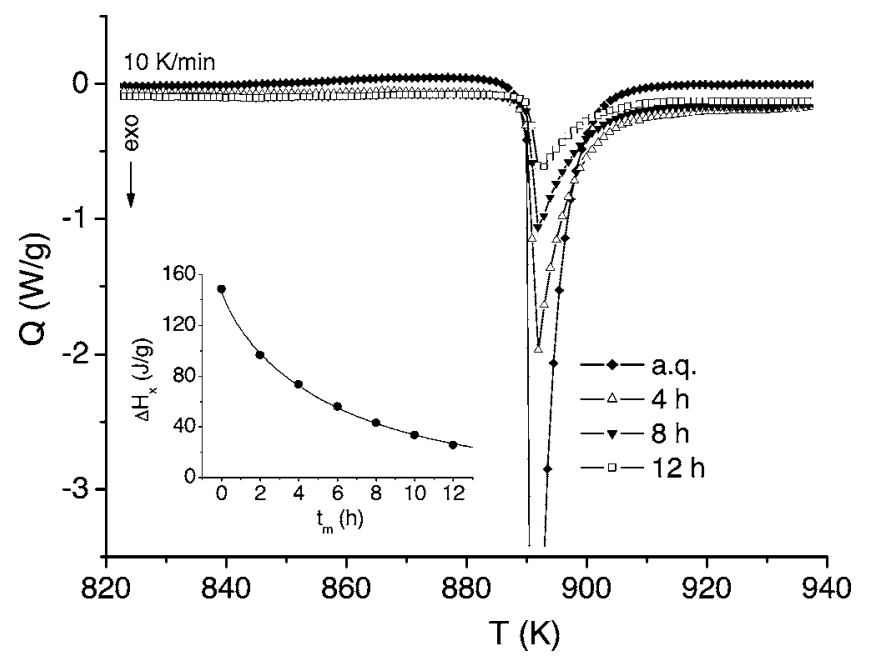

FIG. 4. DSC scans of as-quenched ribbon and powder samples milled for 4, 8 , and $12 \mathrm{~h}$. The inset shows the evolution of the crystallization enthalpy $\Delta H_{x}$ with milling time $t_{m}$. 


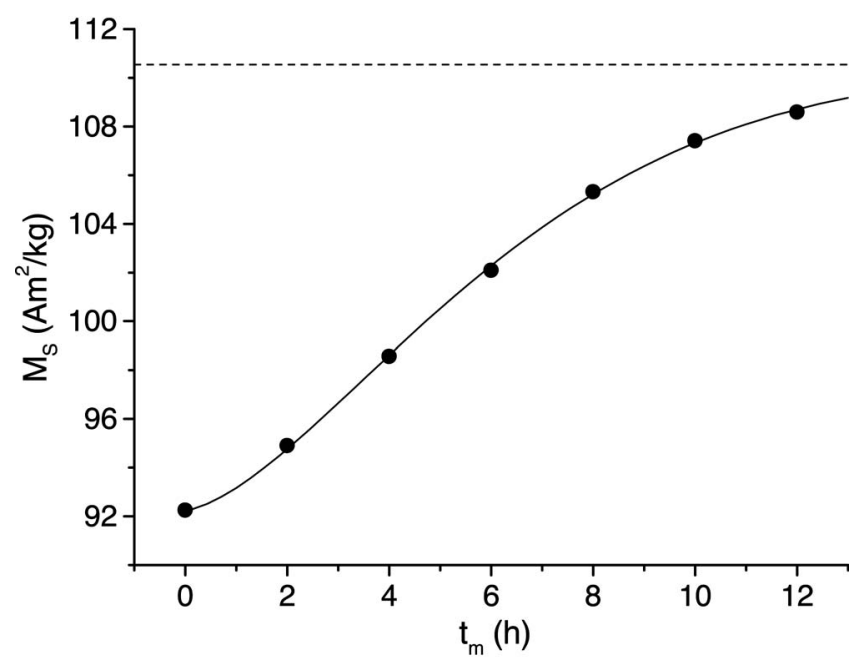

FIG. 5. The saturation magnetization $M_{S}$ as a function of milling time $t_{m}$. The milling time $t_{m}=0 \mathrm{~h}$ corresponds to the as-quenched ribbon. The solid line corresponds to a Johnson-Mehl-Avrami fit of the data.

The saturation magnetization $M_{S}$ of the milled samples as a function of milling time $t_{m}$ is plotted in Fig. 5. From this plot it is evident that $M_{S}$ of the powder samples increases as the fraction of bcc-Fe increases. This behavior is consistent with XRD and DSC measurements.

The thermomagnetic curves of the as-quenched alloy and of milled powders are shown in Fig. 6. The initial decrease of magnetization with temperature is caused by the decrease of the magnetization of the amorphous phase, while it approaches its Curie point $T_{C}^{\mathrm{am}}$ where the paramagnetic state is reached. As can be seen from Fig. 6, the $M(T)$ curves of the powder samples in this temperature range are shifted to higher temperatures and thus exhibit higher values of $T_{C}^{\mathrm{am}}$ in comparison to the as-quenched alloy. Furthermore, after reaching $T_{C}^{\mathrm{am}}$, the magnetization of the powder samples becomes nonzero above the Curie temperature of the amorphous phase. This nonzero value tends to increase for longer milling times. This reflects the fact that the fraction of bcc-Fe formed by BM increases with the milling time. With further increase in temperature, the amorphous phase of the powder

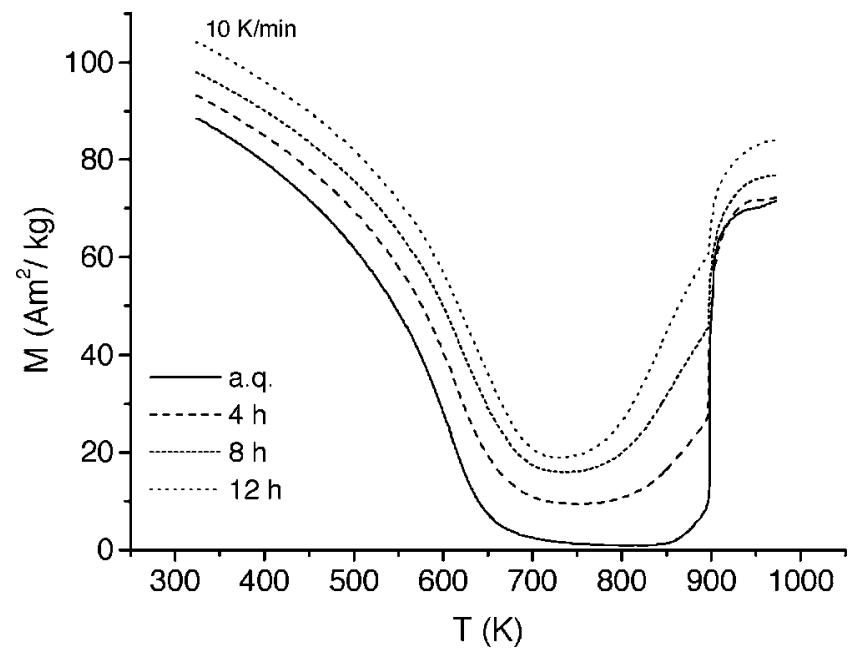

FIG. 6. The thermomagnetic curves of as-quenched ribbon (aq) and powder samples milled for 4,8 , and $12 \mathrm{~h}$.

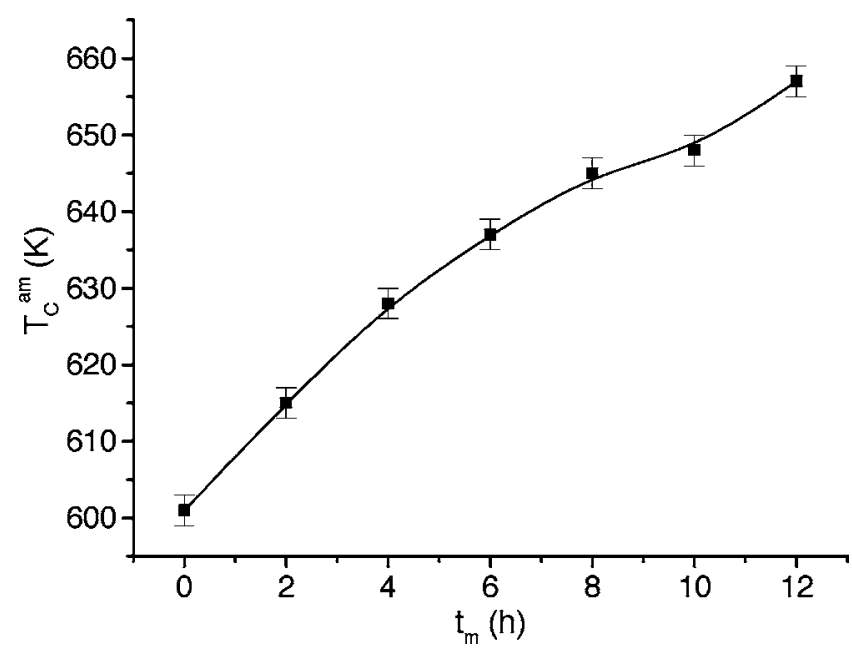

FIG. 7. The Curie temperature of the amorphous phase $T_{C}^{\mathrm{am}}$ as a function of milling time $t_{m}$. The milling time $t_{m}=0 \mathrm{~h}$ corresponds to the as-quenched ribbon.

samples crystallizes, as reflected by the appearance of the relatively high and sharp step in the $M(T)$ curves (Fig. 6). It perfectly correlates with the exothermic peak in the corresponding DSC plots (Fig. 4). Such increase of magnetization above $900 \mathrm{~K}$ reveals that the crystallization of the amorphous residual results in the formation of at least one ferromagnetic phase with a Curie temperature larger than the crystallization temperature. The values of $T_{C}^{\mathrm{am}}$ were extracted from a linear extrapolation of the $M^{1 / \beta}(T)$ curves (with $\beta$ $=0.36)$ to $M^{1 / \beta}(T)=0$ in the temperature range of 500-600 K. The dependence of $T_{C}^{\mathrm{am}}$ as a function of milling time is plotted in Fig. 7. From this graph, it is visible that $\mathrm{BM}$ causes an increase of the value of $T_{C}^{\mathrm{am}}$, and after $12 \mathrm{~h}$ of milling the powder sample exhibits a $T_{C}^{\mathrm{am}}$ that is approximately $55 \mathrm{~K}$ higher compared to the as-quenched alloy.

The observed changes of $T_{C}^{\mathrm{am}}$ reflect the influence of BM on the microstructure of the $\mathrm{Co}_{56} \mathrm{Fe}_{16} \mathrm{Zr}_{8} \mathrm{~B}_{20}$ alloy. It is imaginable that local temperature rises due to repeated ball collisions are responsible for the partial crystallization of amorphous $\mathrm{Co}_{56} \mathrm{Fe}_{16} \mathrm{Zr}_{8} \mathrm{~B}_{20}$ and the observed variations in $T_{C}^{\mathrm{am}}$ with the milling time. The dependences of $T_{C}^{\mathrm{am}}$ for various annealing temperatures and times are presented in Fig. 8. As can be seen from Fig. 8(a), $T_{C}^{\mathrm{am}}$ of isochronally annealed ribbons tends to increase with annealing temperature $T_{\text {an }}$ and saturates at $638 \mathrm{~K}$ after annealing above $813 \mathrm{~K}$. However, isochronal annealings above $833 \mathrm{~K}$ caused the ribbons to crystallize. The next heat treatments were performed at a fixed annealing temperature $T_{\text {an }}=813 \mathrm{~K}$, and the annealing time $t_{\text {an }}$ was varied. The curve shown in Fig. 8(b) reveals that within an experimental error for shorter annealing times $\left(t_{\mathrm{an}}<180 \mathrm{~min}\right)$ an almost linear dependence of $T_{C}^{\mathrm{am}}$ on $\ln \left(t_{\mathrm{an}}\right)$ is seen. The deviation from the linearity became remarkable after a prolonged annealing time. It should be noted here that longer annealing times $\left(t_{\text {an }}>540 \mathrm{~min}\right)$ resulted in the crystallization of the ribbons.

\section{DISCUSSION}

X-ray diffraction experiments using synchrotron radiation clearly demonstrated that BM causes the amorphous 

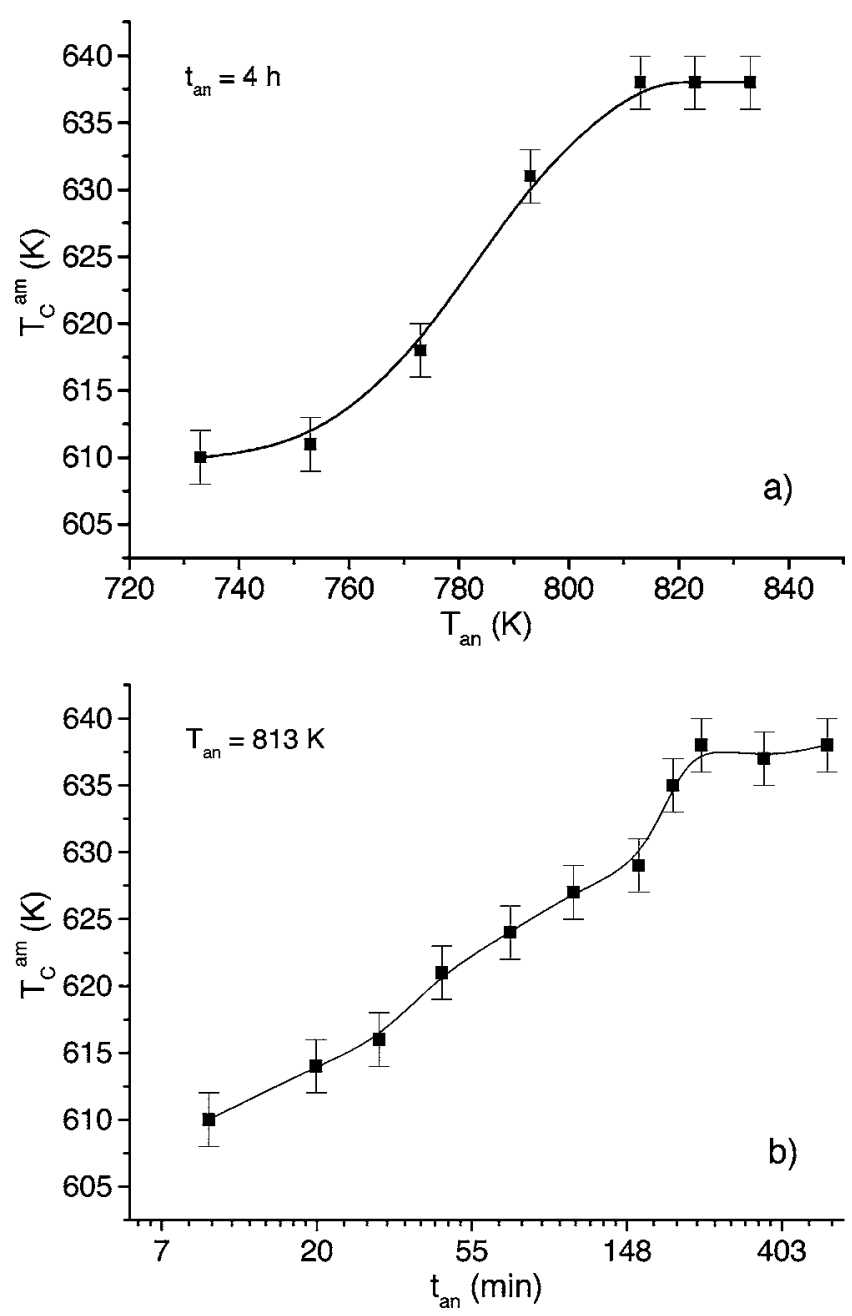

FIG. 8. The Curie temperature of the amorphous phase $T_{C}^{\mathrm{am}}$ of $\mathrm{Co}_{56} \mathrm{Fe}_{16} \mathrm{Zr}_{8} \mathrm{~B}_{20}$ ribbons annealed (a) isochronally for $4 \mathrm{~h}$ at different temperatures $T_{\text {an }}$ and (b) isothermally at $813 \mathrm{~K}$ for different times $t_{\mathrm{an}}$. The lines are drawn to guide the eye.

$\mathrm{Co}_{56} \mathrm{Fe}_{16} \mathrm{Zr}_{8} \mathrm{~B}_{20}$ alloy to gradually crystallize with the increasing milling time. The structure of the powder sample after $12 \mathrm{~h}$ of milling was identified as a mixture of nanocrystalline bcc-Fe grains and the residual amorphous matrix.

The DSC measurements revealed that amorphous $\mathrm{Co}_{56} \mathrm{Fe}_{16} \mathrm{Zr}_{8} \mathrm{~B}_{20}$ crystalizes in one step, as indicated by the presence of a sharp exothermic peak with the onset temperature $T_{x}=890 \mathrm{~K}$ (see Fig. 4). Furthermore, the XRD investigations of thermally crystallized ribbons $(30 \mathrm{~min}$ at $1073 \mathrm{~K}$ ) suggest that crystallization occurs with a single-stage precipitation of bcc-Fe and $\mathrm{Co}_{3} \mathrm{ZrB}_{2}$. Such crystallization was also reported by Inoue et al.. ${ }^{11}$ The powder samples obey the same crystallization route as the starting alloy. The only difference is that the area of the exothermic peaks, which is closely related to the exothermic heat $\Delta H$ released by the ball-milled samples upon crystallization, gradually decreases with the increasing milling time (see inset in Fig. 4). This observation is consistent with an increase in the amount of crystalline bcc-Fe during BM as suggested by $\mathrm{x}$-ray diffraction results.

Since bcc-Fe exhibits a higher $M_{S}$ than the amorphous phase, it was possible to follow the mechanically induced crystallization of the amorphous $\mathrm{Co}_{56} \mathrm{Fe}_{16} \mathrm{Zr}_{8} \mathrm{~B}_{20}$ alloy upon
BM by measuring the saturation magnetization of powder samples (see Fig. 5). Assuming that the total magnetic moment after a certain milling time $t$ is a superposition of the moments of the amorphous fraction $(1-x)$ and the crystallized fraction $x$, the saturation magnetization data can be fitted by a Johnson-Mehl-Avrami model for the transformed fraction (see Fig. 5)

$$
\begin{aligned}
& x(t)=1-\exp \left(-k t^{n}\right), \\
& M(t)=(1-x) M_{\mathrm{aq}}+x M_{\mathrm{cr}},
\end{aligned}
$$

where $M_{\text {aq }}$ is the saturation magnetization of the amorphous ribbon and $M_{\mathrm{cr}}$ is the saturation magnetization of the mechanically crystallized sample. The parameter $k$ is a rate constant and $n$ the Avrami exponent which depends on the mechanism (nucleation and growth) of the crystallization. Since the phase composition and, thus, the saturation magnetization of the thermally crystallized alloy, is different from that of the alloy crystallized mechanically by BM, we left $M_{\mathrm{cr}}$ as a free parameter of the fitting procedure. The fit to the data gives $k=0.051 \pm 0.003 \mathrm{~h}^{-1}, n=1.53 \pm 0.05$, and $M_{\text {cr }}$ $=110.5 \pm 0.5 \mathrm{~A} \mathrm{~m}^{2} \mathrm{~kg}^{-1}$. The dashed line in Fig. 5 corresponds to $M_{\mathrm{cr}}$. The value of the exponent $n$ close to 1.5 is consistent with a zero-nucleation rate ${ }^{12}$ and a crystal growth in all directions from very small dimensions. Friedrich et al. ${ }^{13}$ and Trudeau et al. ${ }^{14}$ reported for the mechanical crystallization of $\mathrm{Fe}_{86} \mathrm{Zr}_{7} \mathrm{~B}_{6} \mathrm{Cu}_{1}$ and $\mathrm{Fe}_{66} \mathrm{Co}_{18} \mathrm{Si}_{1} \mathrm{~B}_{15}$ values of $n$ $=1.50$ and $n=1.46$, respectively. On the other hand, Guo and $\mathrm{Lu}^{15}$ observed an Avrami exponent of $n=1.0$ for the mechanical crystallization of $\mathrm{Fe}_{77.2} \mathrm{Mo}_{0.8} \mathrm{Si}_{9} \mathrm{~B}_{13}$.

It is to be considered whether the observed increase of the saturation magnetization (see Fig. 5) might be caused by a contamination from steel balls and vial. Therefore, let us calculate what should be the iron fraction $x_{\mathrm{Fe}}$ according to that assumption. Inserting the values of the saturation magnetization of iron $\left(M_{\mathrm{Fe}}=222 \mathrm{~A} \mathrm{~m}^{2} \mathrm{~kg}^{-1}\right)$, of the as-quenched ribbon $\left(M_{\mathrm{aq}}=92 \mathrm{~A} \mathrm{~m}^{2} \mathrm{~kg}^{-1}\right)$, and of the observed increase of the saturation magnetization $\left(\Delta M_{S}=16 \mathrm{~A} \mathrm{~m}^{2} \mathrm{~kg}^{-1}\right)$ into the equation $\Delta M_{S}=x_{\mathrm{Fe}} M_{\mathrm{Fe}}-x_{\mathrm{Fe}} M_{\mathrm{aq}}$, we obtain a relatively high value for the iron fraction $x_{\mathrm{Fe}}=12.3 \mathrm{wt} \%$. However, such a high amount of iron should be much better resolved by XRD. DSC and thermomagnetic measurements also indicate that the observed changes upon BM are more related to changes in the amorphous phase (namely, partial crystallization) than to a contamination. Taking into account the type of mill, speed, and duration of milling, such high value of $x_{\mathrm{Fe}}$ could not be explained in the terms of contamination by attrition. It was reported by many works that the magnitude of iron contamination of the powders milled with the steel grinding medium is in the range of 1-4 wt \% (see Chap. 14 of Ref. 1). Despite the fact that the contamination from milling media cannot be completely ruled out, we think that in our BM experiment it plays a minor role.

The observed dependence of $T_{C}^{\mathrm{am}}$ on BM (see Fig. 7) might be due to different influences: (1) change in the alloy composition due to debris from the steel milling balls or vials, (2) a structural change of the amorphous phase induced by the BM, ${ }^{16}$ and (3) crystallization induced directly by the milling process. In our case, the milling time is rather short, 
and thus a debris-induced change of the composition should not be very pronounced. On the other hand, BM may induce structural fluctuations in the amorphous phase, which give rise to fluctuations of the exchange interactions. These, in turn, set the scale for $T_{C}^{\mathrm{am}}$. However, from the shape of the Bethe-Slater curve and the relative positions of $\mathrm{Fe}$ and $\mathrm{Co}$ on the curve it can be inferred that $T_{C}^{\mathrm{am}}$ of Co-based alloys is relatively invariant to disorder compared with Fe-based alloys, ${ }^{17}$ and thus one may conclude that the observed increase of $T_{C}^{\mathrm{am}}$ with the milling time is not correlated to changes in the short-range order of the amorphous phase. As concluded from XRD observations, bcc-Fe nanocrystalline grains are formed during milling. As the amount of the bcc-Fe phase during BM increases, the relative fraction of Co in the amorphous matrix increases too and consequently leads to higher $T_{C}^{\mathrm{am}}$ of the powder samples. Thus, it seems to us that nanocrystallization induced by BM is the most probable reason for the observed behavior of $T_{C}^{\mathrm{am}}$. Thermomagnetic measurements on heat-treated ribbons (see Fig. 8) showed that annealing below the crystallization temperature also increases $T_{C}^{\mathrm{am}}$. The removal of stress and free volumes, which originate from rapid quenching when preparing ribbons, brings the amorphous phase towards a more relaxed state exhibiting a higher $T_{C}^{\mathrm{am}}$. Finally, the comparison of the influences of $\mathrm{BM}$ and conventional annealing on amorphous alloy indicates that the increase of $T_{C}^{\mathrm{am}}$ achieved by BM (approximately $55 \mathrm{~K}$, Fig. 7) is significantly larger than that of conventional annealing (approximately $35 \mathrm{~K}$, Fig. 8). This suggests that the observed increase of $T_{C}^{\mathrm{am}}$ in the case of BM is mainly due to nanocrystallization, whereas it is caused by the relaxation of the amorphous phase in the case of conventional annealing. BM is stochastic and of a rather complex nature. Thus, its influence on the microstructure of the milled material cannot be simply replaced by conventional annealing. Rather, the effects of BM should be treated separately from the effect of a thermal treatment.

It is well known that the deformation of metallic glasses at temperatures lower than the glass transition temperature is characterized by the formation and movement of highly localized shear bands. ${ }^{18,19}$ When shear bands begin to form in a metallic glass, the strength of the material inside the shear band is reduced and further deformation takes place preferentially along the shear bands. ${ }^{20}$ This suggests that during the deformation process, the viscous flow inside the shear bands is enhanced and structural changes may occur within the shear bands. Furthermore, the local temperature rises, when the milled material is entrapped between the colliding ball and vial, may increase the diffusivity and enhance the crystallization inside the shear bands. Finally, we conclude that the $\mathrm{BM}$ driven crystallization of the amorphous $\mathrm{Co}_{56} \mathrm{Fe}_{16} \mathrm{Zr}_{8} \mathrm{~B}_{20}$ alloy results from the simultaneous action of local pressure and local temperature, which are produced by the collision of steel balls.

\section{CONCLUSION}

Our results show that ball milling is an alternative route for gradual devitrification of an amorphous $\mathrm{Co}_{56} \mathrm{Fe}_{16} \mathrm{Zr}_{8} \mathrm{~B}_{20}$ alloy. The fraction of the nanocrystalline bcc-Fe phase was found to increase with the milling time and was fit to the Johnson-Mehl-Avrami (JMA) model. A JMA model was applied to fit the temperature-time characteristics of the observed amorphous to crystalline transformation. An Avrami coefficient $n$ of 1.53 indicates an isotropic grain growth of a constant number nuclei. Furthermore, our structural investigations demonstrate that a composite (bcc-Fe nanocrystals embedded in an amorphous matrix) material may be prepared (in an easily controllable way) by high-energy milling of an initially amorphous alloy. It may be expected that the obtained material will have unique properties presumably different from the crystalline as well as the amorphous precursors. We think that the powder material prepared in this way may be used as a precursor to prepare soft magnetic bulk materials exhibiting soft magnetic properties comparable to those of as-quenched ribbons and in some aspects exceeding their performance (e.g., higher Curie point and saturation magnetization).

\section{ACKNOWLEDGMENTS}

This work was supported by the Science and Technology Assistance Agency under Contract No. APVT-20-008404 and partially supported by Project No. VEGA 1/1021/04. The support from the Marie Curie Fellowship Programme of the European Community (Improving Human Research Potential) under the Contract No. HPMD-CT-2001-00089 is also acknowledged.

${ }^{1}$ C. Suryanarayana, Prog. Mater. Sci. 46, 1 (2001).

${ }^{2}$ C. C. Koch, Materials Science and Technology A comprehensive Treatment (VCH Verlagsgesellschaft, Weinheim, Germany, 1991), Vol. 15, pp. 193-245.

${ }^{3}$ M. L. Trudeau, R. Schulz, D. Dussault, and A. V. Neste, Phys. Rev. Lett. 64, 99 (1990).

${ }^{4}$ Y. He, G. J. Shiflet, and S. J. Poon, Acta Metall. Mater. 43, 83 (1995).

${ }^{5}$ A. Inoue, T. Zhang, H. Koshiba, and A. Makino, J. Appl. Phys. 83, 6326 (1998a).

${ }^{6}$ J. Bednarčík, P. Kollár, S. Roth, and J. Eckert, Phys. Status Solidi A 199 , 299 (2003).

${ }^{7}$ A. P. Hammersley, S. O. Svensson, M. Hanfland, A. N. Fitch, and D. Häusetmann, High Press. Res. 14, 235 (1996).

${ }^{8}$ T. E. Faber and J. M. Zimman, Philos. Mag. 11, 153 (1965).

${ }^{9}$ G. Herzer, IEEE Trans. Magn. 25, 3327 (1989).

${ }^{10}$ M. Imafuku, K. Yaoita, S. Sato, W. Zhang, A. Inoue, and Y. Waseda, Mater. Sci. Eng., A 304-306, 660 (2001).

${ }^{11}$ A. Inoue, H. Koshiba, T. Itoi, and A. Makino, Appl. Phys. Lett. 73, 744 (1998b).

${ }^{12}$ J. W. Christian, The Theory of Transformation in Metals and Alloys (Pergamon, Oxford, United Kingdom, 1974).

${ }^{13}$ J. Friedrich, U. Herr, and K. Samwer, J. Appl. Phys. 87, 2464 (2000).

${ }^{14}$ M. L. Trudeau, J. Y. Huot, R. Schulz, D. Dussault, A. V. Neste, and G. L'Espérance, Phys. Rev. B 45, 4626 (1992).

${ }^{15}$ F. Q. Guo and K. Lu, Metall. Mater. Trans. A 28A, 1123 (1997).

${ }^{16}$ G. J. Fan, M. X. Quan, and Z. Q. Zhou, Appl. Phys. Lett. 68, 319 (1996).

${ }^{17}$ K. A. Gallagher, M. Willard, V. Zabenkin, D. Laughlin, and M. McHenry, J. Appl. Phys. 85, 5130 (1999).

${ }^{18}$ H. Spaepen, Acta Metall. 25, 407 (1977)

${ }^{19}$ A. S. Argon, Acta Metall. 27, 47 (1979).

${ }^{20}$ C. A. Pampillo and H. S. Chen, Mater. Sci. Eng. 13, 181 (1974). 